\title{
Comparative efficiency of fish trap with different funnel designs
}

\author{
D. ARUNJENISH, N. NEETHISELVAN, B. SUNDARAMOORTHY, P. JAWAHAR AND \\ T. RAVIKUMAR \\ Fisheries College and Research Institute, Tamil Nadu Fisheries University, Thoothukudi - 628001 \\ Tamil Nadu, India \\ e-mail: dajenish@gmail.com
}

\begin{abstract}
The efficiency of four different funnel designs viz., rectangular, oval, heart-in and circular shaped funnels were tested in a serial collapsible fish trap through fishing trials conducted in a coastal fishing ground off Mandapam in Tamil Nadu, south-west coast of India. A total of 24 fishing operations were carried out. Significant difference in overall catch rate of experimental trap with respect to funnel designs could be observed $(\mathrm{p}<0.05)$. Among four types of funnels tested with the constant rear end funnel perimeter of $560 \mathrm{~mm}$, traps with oval funnel caught more number of fishes (121 nos. in 24 soaking days) than those fitted with rectangular, heart-in shaped and circular type of funnels with $37 ; 82$ and 70 nos. in 24 soaking days respectively. The study revealed that oval shaped funnel was superior to the other funnel designs with 560 mm circumference.
\end{abstract}

Keywords: Catching efficiency, Fishing trial, Funnel design, Serial collapsible fish trap

Trap fishing is an excellent low energy fishing method compared to active fishing methods. Trap is an impounding device into which fishes are lured and afterwards escapement is made difficult because of the presence of a non-return device fixed at the entrance. Fish trap has been reported to be the principal fishing device throughout the Bahamian and Caribbean islands as it was found to be an efficient device for capturing fishes in areas where coral formation prevents the use of trawls and other nets (Munro, 1974). In New South Wales of Australia, the majority of ocean leather jackets were fished using demersal fish traps (Miller and Stewart, 2009).

Development of collapsible trap fishing technique is of recent origin. Caesar and Oxenford (2005) reported that the collapsible traps were found to catch significantly larger fishes than traditional traps. Collapsible traps have been found to be ideal for small scale fishing in reef areas of East Nusa Tenggara Province, Thailand (Hutubessy and Mosse, 2007). Further, a box-shaped collapsible pot has been reported to be one of the most popular types of trap used in coastal areas of Thailand owing to good catch rate, low cost and high portability which allow loading of large number of traps over the deck of small vessels (Boutson, 2005). The design of the entrance was found to be of great importance for the catching efficiency of the pots (Furevik and Lokkeborg, 1994). The present investigation tested the effectiveness of four different funnel designs viz., rectangular, oval, heart-in and circular shaped funnels with $560 \mathrm{~mm}$ perimeter using serial collapsible fish trap in the coastal fishing ground off Mandapam Coast of Tamil Nadu.

The present study was carried out for six months from November 2016 to April 2017. The traps were operated from a Vallam having $6.7 \mathrm{~m}$ length overall (LOA), $1.7 \mathrm{~m}$ beam and $1.2 \mathrm{~m}$ depth. The experimental traps were operated in fishing grounds three nautical miles off the coast of Mandapam, Tamil Nadu, India. The total soaking duration of the trap was kept as $24 \mathrm{~h}$ for all fishing trials. Two units were fabricated, with each unit having two sections in serially connected condition. The first unit of the experimental trap had rectangular shaped funnel in one section and oval shaped funnel in another section (Fig. 1). The second unit had heart-in shaped funnel in one section and circular shaped funnel in another section (Fig. 2). A pair of steel tubes with length of $90 \mathrm{~cm}$ each and another pair having length of $60 \mathrm{~cm}$ were used for the fabrication of trap. The four pieces were joined together to form a rectangular frame by welding. Seven frames were used for making a serial trap so as to have six chambers per trap unit. Blue polyethylene webbing having square meshes of $50 \mathrm{~mm}$ mesh size with 112 meshes in length and 88 meshes in height was joined horizontally by folding their ends together so as to form a long bag with the help of a polyethylene twine of size 23 Tex $\times 2 \times 3$. The distance between the two frames was kept as $0.56 \mathrm{~m}$ with 19 meshes. The front face of the trap had 37 meshes in length and 19 meshes in height. To make the collection bags at the end of the serial trap assembly, webbing having 


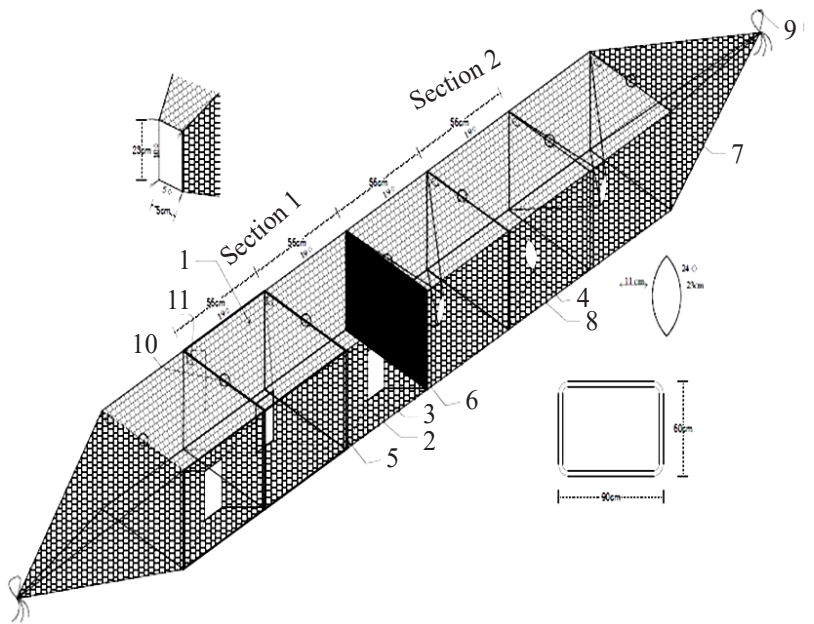

1. Covering webbing (Polyethylene (PE) 23 Tex x $3^{*} 3$ )(Blue colour): 50mm mesh size

2. Trap entrance webing (Polyethylene) (Dark blue colour): $50 \mathrm{~mm}$ mesh size

3. Trap entrance (Rectangular shaped)

4. Trap entrance (Elliptical shaped)

5. PVC (Poly vinyl chloride) frames

6. Partition in between two type trap

7. Collection bag (Polyethylene (Dark blue colour):50 $\mathrm{mm}$ mesh size

8. Lacing twine (Nylon (PA) 23 Tex x $3^{*} 3$

9. Hauling rope (Polyethylene): $12 \mathrm{~mm}$ dia

10. Bait bag

11. Plastic float

Fig. 1. Experimental serial collapsible fish trap with rectangular and oval shaped rear end mouth opening (Unit 1)

the dimensions of 130 meshes along length and 50 meshes in height was seamed to form a single cylindrical bag. A $12 \mathrm{~mm}$ polyethylene rope was passed through the end meshes of the collection bag so as to enable closing and opening.

The front face of each of the trap units were cut and removed on alternative side so that each of the adjacent traps had the entrance in the opposite side. Funnels of both trap units were designed using polyethylene webbing

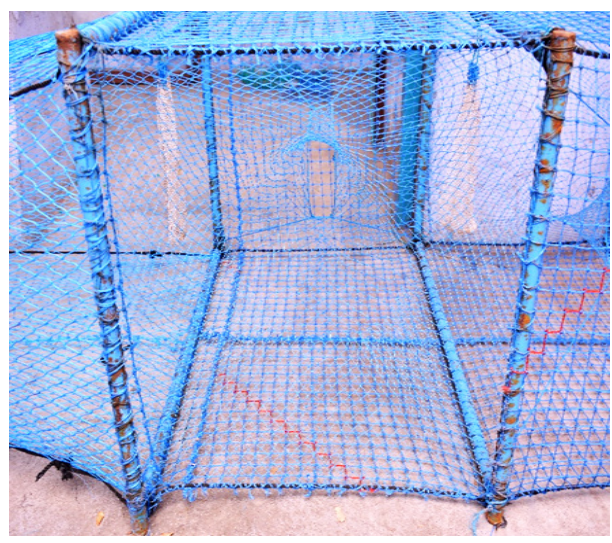

Fig. 3. Rectangular funnel

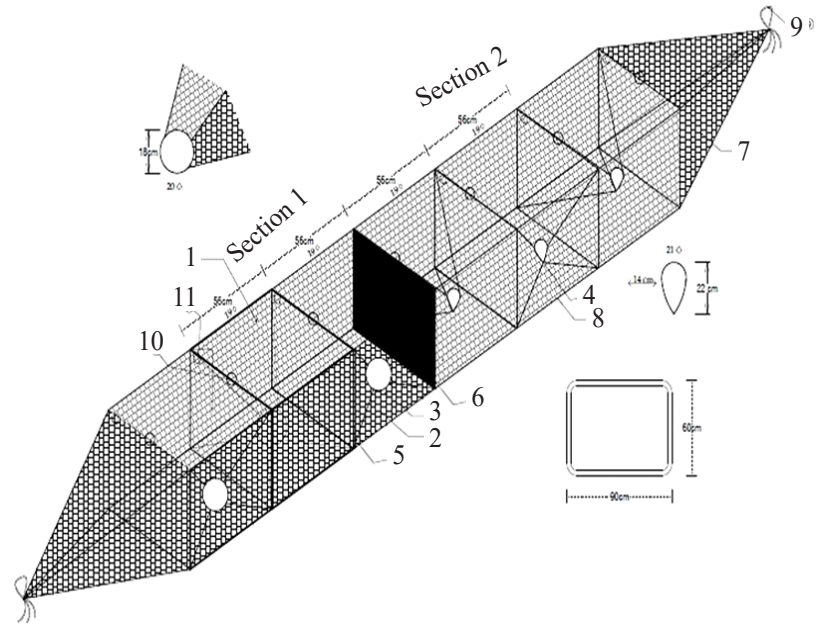

1. Covering webbing (Polyethylene (PE) 23 Tex x $3^{*} 3$ )(Blue colour): 50mm mesh size

2. Trap entrance webing (Polyethylene) (Dark blue colour): $50 \mathrm{~mm}$ mesh size

3. Trap entrance (Circular shaped)

4. Trap entrance (Heartine shaped)

5. PVC (Poly vinyl chloride) frames

6. Partition in between two type trap

7. Collection bag (Polyethylene (Dark blue colour):50 $\mathrm{mm}$ mesh size

8. Lacing twine (Nylon (PA)23 Tex x 3*3

9. Hauling rope (Polyethylene): $12 \mathrm{~mm}$ dia

10. Bait bag

11. Plastic float

Fig. 2. Experimental serial collapsible fish trap with heart-in and circular shaped rear end funnel opening (Unit 2)

of $30 \mathrm{~mm}$ mesh size made up of twine with thickness of $0.25 \mathrm{~mm}$. A partition was made with polyethylene webbing in between $3^{\text {rd }}$ and $4^{\text {th }}$ frame so as to have two different sections in the serial trap to facilitate two types of funnels. A total of four shapes of funnels were fabricated. In the first trap assembly, the first section consisted of 3 chambers, each of which was fitted with rectangular funnel while the three chambers of $2^{\text {nd }}$ section were fitted with oval funnels (Fig. 3 and 4). In the second trap assembly, first three chambers were fitted with heart-in shaped funnels while

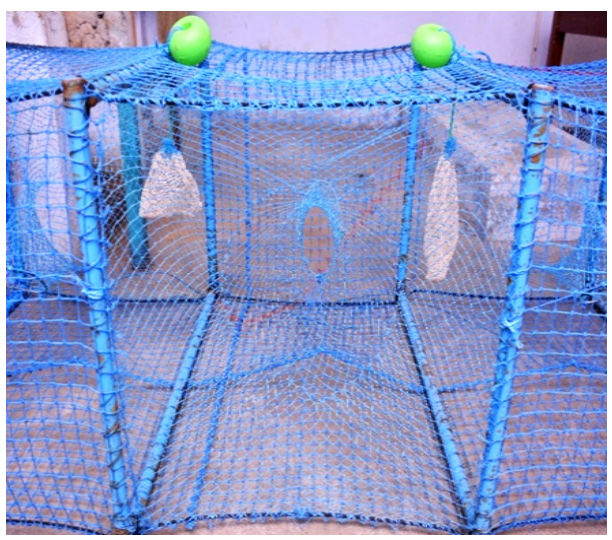

Fig. 4. Oval funnel 
the rest of the three chambers were fitted with circular funnels (Fig. 5 and 6). To design rectangular funnel, 3 net panels were joined horizontally with different take up ratio. The first panel consisted of 95 meshes in length and 11 meshes in depth. The second panel consisted of 46 meshes in length and 7 meshes in depth. Both first and second panels were joined with the take up ratio of $2 / 1$. The third panel consisted of 31 meshes in length and 5 meshes in depth and it was joined with second panel with take up ratio of $3 / 2$. The Rectangular funnel had base width of $5 \mathrm{~cm}$ ( 5 meshes) and height of $23 \mathrm{~cm}$ (10 meshes). The four corners of rectangular funnel were tied with the help of $2 \mathrm{~mm}$ polyethylene twine to the respective opposite corners of the trap chamber. The rectangular funnel did not have any tilt at the rear end. However, all the other funnels were set to have tilt downwards. To facilitate this, an additional piece of webbing was provided in the rear end of the funnels. The fourth panel of oval funnels had 19 meshes in length and 8 meshes in depth and it was joined with the third panel with the take up ratio of $3 / 2$. The rear funnel opening of oval funnels had the mid opening width of $11 \mathrm{~cm}$. To facilitate the oval mouth opening, an oval ring made up of $0.4 \mathrm{~cm}$ dia iron having $56 \mathrm{~cm}$ length

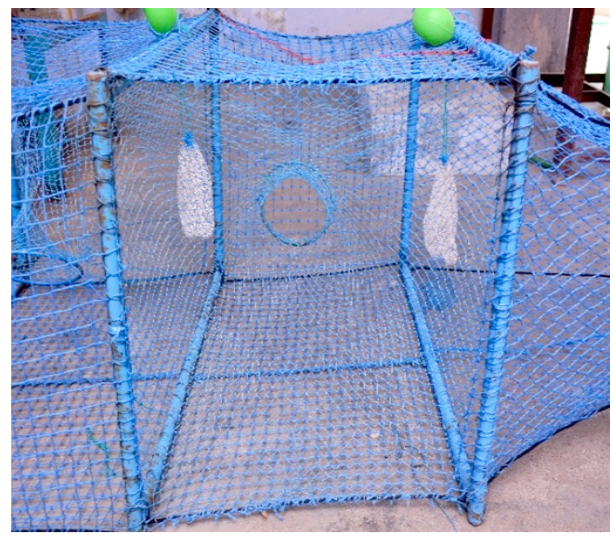

Fig. 5. Heart-in shaped funnel

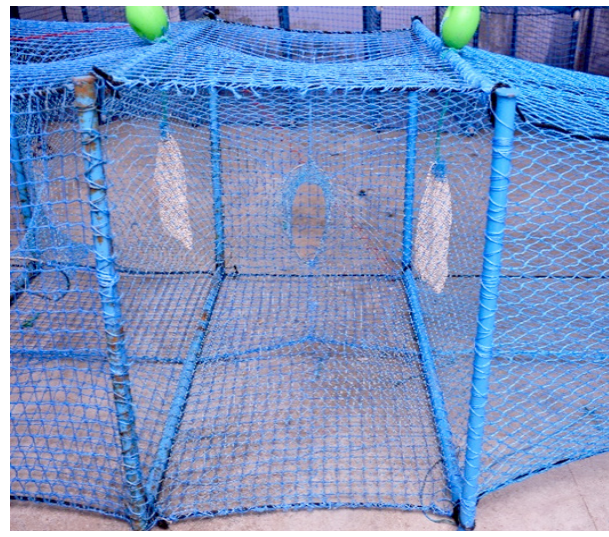

Fig. 6. Circular funnel was used. In the case of heart-in shaped funnels, the fourth funnel had 22 meshes in length and 5.5 meshes in depth. It was joined with the third panel with the take up ratio of $4 / 3$. The rear opening of heart-in shaped funnels had the mid opening width of $14 \mathrm{~cm}$. To facilitate the heart-in shaped mouth opening, a heart-in shaped ring made up of $0.4 \mathrm{~cm}$ dia iron of $56 \mathrm{~cm}$ length was used. In circular funnels, the fourth panel had 13 meshes in length and 5 meshes in depth and it was connected to the third panel with the take up ratio of $2 / 1$. The rear funnel opening of circular funnels had $18 \mathrm{~cm}$ dia. To facilitate the circular mouth opening, a circular ring made up of $0.5 \mathrm{~cm}$ dia iron of $56 \mathrm{~cm}$ length was used. After lacing the lateral ends of the combined funnel piece, the rear end funnel circumference was maintained as $56 \mathrm{~cm}$ for all four types of entrances.

In the present study, the four different funnel designs namely rectangular, oval, heart-in and circular shaped funnels showed significant impact on the catch rate $(p<0.01)$. Among the four types of funnels, oval shaped funnel was found to be more efficient than the other type of funnels recording a catch rate of 121 nos. in 24 soaking days. Whereas the other types of funnels viz., rectangular, heart-in shaped and circular funnels caught 37;82 and 70 nos. in 24 soaking days respectively (Table 1). In almost all the months during the study period, the oval funnel recorded highest catch in terms of number (Fig. 7) with maximum catch of 34 nos. in 4 soaking days was recorded in November. Mariappan et al. (2016) also reported that the rectangular funnel shape rear end opening had highest catch rate (342 nos. in 20 soaking days) than elliptical shaped rear end opening (99 nos. in 20 soaking days). Sheaves (2014) reported on the advantage of horse neck funnels in

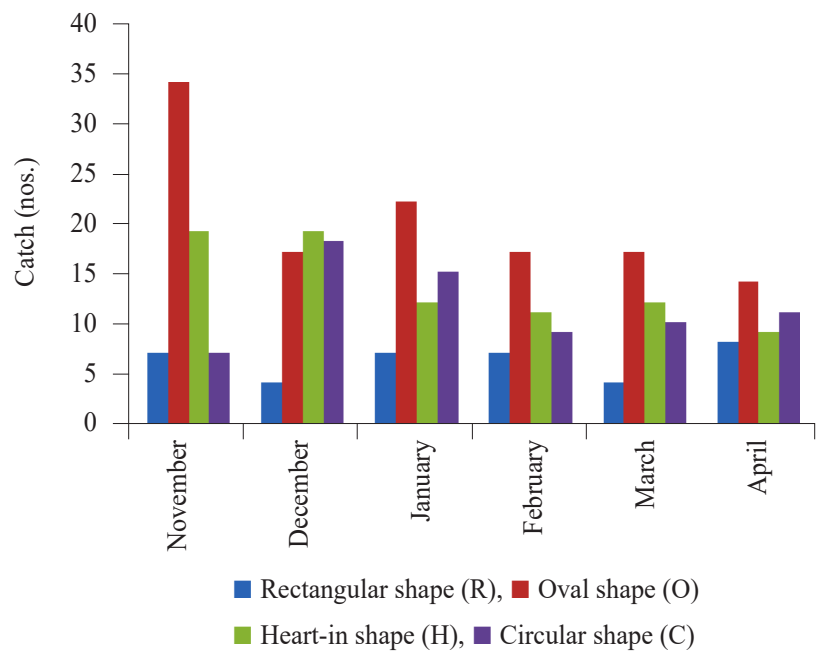

Fig. 7. Catch particulars of trap fitted with funnels having different rear end mouth opening during different months 
Table 1. Catch particulars (in nos. and weight in $\mathrm{kg}$ ) of trap fitted with funnels having four different shapes of rear end openings

\begin{tabular}{|c|c|c|c|c|c|c|c|c|c|c|}
\hline \multirow{3}{*}{ Species } & \multicolumn{8}{|c|}{ Shape of rear end funnel opening } & \multirow{2}{*}{\multicolumn{2}{|c|}{ Total }} \\
\hline & \multicolumn{2}{|c|}{ Rectangular } & \multicolumn{2}{|c|}{ Oval } & \multicolumn{2}{|c|}{ Heart-in } & \multicolumn{2}{|c|}{ Circular } & & \\
\hline & Nos. & $\begin{array}{l}\text { Weight } \\
(\mathrm{kg})\end{array}$ & Nos. & $\begin{array}{l}\text { Weight } \\
(\mathrm{kg})\end{array}$ & Nos. & $\begin{array}{l}\text { Weight } \\
(\mathrm{kg})\end{array}$ & Nos. & $\begin{array}{l}\text { Weight } \\
(\mathrm{kg})\end{array}$ & Nos. & $\begin{array}{l}\text { Weight } \\
(\mathrm{kg})\end{array}$ \\
\hline Acanthurus mata (=bleekeri) & 6 & 0.72 & 10 & 1.32 & 7 & 1 & 11 & 1.5 & 34 & 4.54 \\
\hline Epinephelus malabaricus & 4 & 0.84 & 25 & 5.9 & 20 & 3.8 & 10 & 1.7 & 59 & 12.24 \\
\hline Abudefduf saxatilis & 4 & 0.13 & 11 & 0.14 & 6 & 0.28 & 12 & 0.42 & 33 & 0.97 \\
\hline Chaetodon collare & 3 & 0.14 & 6 & 0.1 & 5 & 0.17 & 3 & 0.13 & 17 & 0.54 \\
\hline Psammoperca waigiensis & - & - & 1 & 0.15 & - & - & - & - & 1 & 0.15 \\
\hline Heniochus acuminatus & - & - & 3 & 0.08 & - & - & - & - & 3 & 0.08 \\
\hline Lutjanus sp. & - & - & 3 & 0.3 & 1 & 0.85 & - & - & 4 & 1.15 \\
\hline Parupeneus indicus & 3 & 0.51 & 9 & 1.7 & 3 & 0.66 & 1 & 0.21 & 16 & 3.08 \\
\hline Plotosus lineatus & 6 & 1 & 14 & 2.7 & 10 & 2.2 & 13 & 2.66 & 43 & 8.56 \\
\hline Pterois russelii & 3 & 0.38 & 3 & 0.5 & 4 & 0.51 & - & - & 10 & 1.39 \\
\hline Scarus ghobban & - & - & 9 & 2.16 & 8 & 1.3 & 4 & 0.7 & 21 & 4.16 \\
\hline Siganus canaliculatus & 5 & 0.42 & 20 & 2.74 & 16 & 1.5 & 9 & 1.3 & 50 & 5.96 \\
\hline Zebrasoma velifer & 3 & 0.12 & 4 & 0.29 & - & - & 7 & 0.31 & 14 & 0.72 \\
\hline Cheilinus sp. & - & - & 2 & 0.5 & 1 & 0.65 & - & - & 3 & 1.15 \\
\hline Plectorhinchus sp. & - & - & 1 & 1 & 1 & 0.7 & - & - & 2 & 1.7 \\
\hline Total & 37 & 4.26 & 121 & 19.58 & 82 & 13.62 & 70 & 8.93 & 310 & 46.39 \\
\hline
\end{tabular}

Note: Catch expressed for 3 chambers/24 soaking days

retaining fish in traps by reducing escapement, while fish in traps with straight funnels probably showed escapement more easily. The reason could be that the posterior end of the horse neck funnel was kept downwards to retain the fishes. In the present study also the oval, heart-in shaped and circular funnels which were fitted facing downwards, were found to be more efficient than the rectangular funnel design in both unit-1 and unit-2 traps. Among these three funnel designs (oval, heart-in shaped and circular), the traps fitted with the oval shaped funnel facilitated easy entry of fishes and recorded comparatively higher catch rates. From the results of the study, it may be concluded that oval shaped funnel with the rear end perimeter of $560 \mathrm{~mm}$ is more efficient for serial collapsible fish traps.

\section{Acknowledgements}

The authors record deep sense of gratitude to Mr. Manimaran, fisherman of mandapam for his continuous help in conducting the fishing trials. The financial assistance rendered through ICAR Development Grant of FC and RI, Thoothukudi (2015-16) for the fabrication of experimental traps is acknowledged.

\section{References}

Boutson, A., Arimoto, T., Mahasaeasde, C. and Tankijjanuki 2005. Size and species selectivity by improving collapsible trap design for blue swimming crab in Thailand. Tokyo
University of Marine science and Technology, Tokyo, Japan and Faculty of Fisheries, Kaetsart University, Bangkok, Thailand.

Caesar, E. D. and Oxenford, H. A. 2005. Testing a collapsible trap design in the deep demersal trap fishery of Tobago, Eastern Caribbean. Proceedings of the Gulf and Caribbean Fisheries Institute, 56: 117-132.

Furevik, D. M. and Lokkerborgl, S. 1994. Fishing trials in Norway for torsk (Brosme brosme) and cod (Gadus morhua) using baited commercial pots. Fish. Res., 19: 219-229.

Hutubessy, B. G. and Mosse, J. W. 2007. An experimental fishing operation of collapsible trap for capture of coral fish. J. fish. Sci., IX(2): 267-273.

Mariappan, S., Neethiselvan, N., Sundaramoorthy, B., Athithan, S. and Ravikumar, T. 2016. Comparision of catching efficiency of collapsible serial fish traps baited with two different baits., J. Exp. Zool. India, 19: 597-601.

Miller, M. E. and Stewart, J. 2009. The commercial fishery for ocean leather jackets (Nelusetta ayraudi, Monacanthidae). Asian Fish. Sci., 22:257-264.

Munro, J. L. 1974. The mode of operation of Antillean fish traps and the relationships between ingress, escapement, catch and soak. J. Cons. Int. Explor. Mer., 35(3): 337-350.

Sheaves, M. 2014. Effect of design modifications and soak time variations on Antillean-Z fish trap performance in a tropical estuary. Bull. Mar. Sci., 56(2): 475-489. 